Research Article

\title{
Coupled Vibration Behavior of Hot Rolling Mill Rolls under Multinonlinear Effects
}

\author{
Rongrong Peng, ${ }^{1,2}$ Xingzhong Zhang $\mathbb{D}^{1}{ }^{1}$ and Peiming Shi ${ }^{3}$ \\ ${ }^{1}$ National Engineering Research Center for Equipment and Technology of Cold Strip Rolling, Yanshan University, \\ Qinhuangdao, Hebei, China \\ ${ }^{2}$ School of Education, Nanchang Institute of Science \& Technology, Nanchang, Jiangxi, China \\ ${ }^{3}$ College of Electrical Engineering, Yanshan University, Qinhuangdao, Hebei, China
}

Correspondence should be addressed to Xingzhong Zhang; zhangxzh@ysu.edu.cn

Received 18 January 2020; Revised 7 May 2020; Accepted 25 May 2020; Published 10 June 2020

Academic Editor: Laurent Mevel

Copyright (c) 2020 Rongrong Peng et al. This is an open access article distributed under the Creative Commons Attribution License, which permits unrestricted use, distribution, and reproduction in any medium, provided the original work is properly cited.

\begin{abstract}
A coupled vibration model of hot rolling mill rolls under multiple nonlinear effects is established by considering the nonlinear spring force produced by the hydraulic cylinder, the nonlinear friction between the work rolls, the dynamic variation of rolling force, and the effect of external excitation as well as according to the structural constraints of a four-high hot rolling mill in the vertical and horizontal directions. The amplitude-frequency response equation of rolling mill rolls is determined by using a multiple-scale approximation method. Furthermore, use of actual data for simulation indicates that the internal resonance is the main cause of coupling vibration of the rolling mill rolls. In addition, changes in the movement displacement of the hydraulic cylinder and the coupling parameters strongly affect the coupling system of the rolling mill rolls. Finally, the study of the dynamic bifurcation characteristics of the rolling mill rolls indicates that, with varying external excitation amplitude, the vibration of rolls alternates between periodic motion, period-doubling motion, and chaotic motion in both vertical and horizontal directions. This is one of the reasons for the appearance of periodic light and dark stripes on the strip surface. Furthermore, the range of the external excitation amplitude $\left(F_{0}\right)$ at which the rolling mill roll system vibrates violently, that is, $5.68 e 5 \mathrm{~N}<F_{0}<5.84 e 5 \mathrm{~N}$ and $F_{0}>6.12 e 5 \mathrm{~N}$, must be avoided. The research results can provide a theoretical reference for further exploration of the coupling vibration mechanism of hot rolling mills.
\end{abstract}

\section{Introduction}

Hot rolling is an important process in the manufacturing and processing of steel strips. It is a high-temperature and large-reduction process, which imparts large fluidity in the workpiece. In addition, with the application of various new processing technologies, rolling mill vibration is an inevitable problem, which potentially loosens and wears out the mechanical parts, shortens the rolling mill life, and causes vibration of steel strips, thereby reducing the overall product quality and accuracy [1-3].

Most studies on rolling mill vibration focus on a single vibration system, such as vertical, horizontal, or torsional vibration. For instance, Sun et al. considered the interaction between strip tension and thickness and analyzed the effect of multiple-source external disturbance on rolling mill vibration; they established a vertical vibration model of the rolling mill and further improved the control accuracy of tension and thickness of the hot rolling mill through optimization design [4]. Fan et al. analyzed and calculated the structural stability of hot rolling mill rolls and revealed that the gap between the framework and rolling mill rolls can cause the phenomenon of "vibration jump," which destroys the balance of a rolling mill system [5]. Shi et al. studied the nonlinear torsional vibration characteristics of the main drive system of a rolling mill under different connection angles, damping coefficients, and friction force [6, 7]. Under continuous and high-speed rolling, different forms of coupled chatter are generated $[8,9]$. This coupled vibration contributes to the low accuracy of a vibration model 
established on the basis of a single vibration system. Moreover, the research conclusions derived from such models cannot fully explain the complex nonlinear characteristics of rolling mill vibration. To address this problem, some research has been conducted on the chatter mechanism and behavior of coupled vibration [10-12]. Yun et al. established a 2-degree-of-freedom (DOF) linear coupling vibration model by considering the coupling effect of longitudinal and transverse movements of the roll and the effect of rolling speed on the rolling process $[13,14]$. Yang et al. established a rolling mill model, including a rolling process model, a mill stand model, and a hydraulic servo system model, and they analyzed the effect of different working conditions on the coupling model [15]. Liu et al. considered the interaction between rolling mill structure vibration and workpiece vibration, proposed a model of workpiece-roll coupling vibration, studied the transition and bifurcation characteristics of vibration under the main resonance conditions, and introduced time-delay feedback control to suppress rolling mill vibration [16]. Wang et al. considered the friction force due to the roughness between rolls and the work roll movement on the basis of the rolling theory and lubrication theory. They established a coupling vibration model of the rolling interface under unsteady lubrication and the effect of multiple factors [17]. In addition, Lu et al. established a coupling vibration model of the dynamic rolling process and nonlinear vibration parameters and analyzed the bifurcation characteristics and stability of the vibration system using the Hopf bifurcation theorem [18]. In conclusion, although some achievements have been realized in the exploration of the coupling vibration mechanism of rolling mill rolls, there are still some limitations or problems with existing models and studies. Therefore, the complex vibration behavior of a rolling mill itself needs to be further explored and verified from different perspectives.

In this study, we consider the effects of the nonlinear spring force of the hydraulic cylinder of a rolling mill, the nonlinear friction force between rolls, the nonlinear rolling force, and the structural constraints of the rolling mill and establish a coupling vibration model of a four-high hot rolling mill. We investigate the effects of tuning parameters, nonlinear stiffness, and coupling parameters on the amplitude-frequency characteristics of the vibration system. The simulation results show that a process of energy exchange occurs between the vertical and horizontal directions of the rolling mill vibration system. When the vibration parameters change, a jumping phenomenon occurs in both directions, causing instability of the coupling vibration system of the rolling mill. A change in the nonlinear spring force coefficient of the hydraulic cylinder considerably affects the vibration state of the rolling mill rolls, and changes in the coupling parameters lead to the complex nonlinear phenomenon of the vibration system. Thus, the coupling vibration model of a hot rolling mill established in this paper is confirmed to be effective. Finally, the bifurcation and chaos behavior of the coupled vibration system of the rolling mill under dynamic external excitation are studied. It is found that different periodic motions exist and the vibration alternates among different forms, which is one of the reasons for the appearance of periodic light and dark stripes on the strip surface. The results of this study can provide certain theoretical reference and technical support for reducing or restraining rolling mill vibration.

\section{Vibration Modeling of Hot Rolling Mill Rolls}

The mechanical structure of a hot rolling mill can be simply illustrated as shown in Figure 1. In a rolling mill, the cylindrical block of the hydraulic cylinder is placed on the bearing bracket of the upper backup roll, and the piston is placed against the heel block under the mill stand. Therefore, the force is transmitted to the strip through the backup rolls and the upper and lower work rolls; then, the gap between the two work rolls is varied to enable rolling of strips to different thickness and specifications. Hence, the effect of nonlinear forces of the hydraulic system in the vertical direction cannot be ignored in the vibration model of rolling mill rolls.

Furthermore, because the diameter and rotation speed of the backup rolls and work rolls differ, when the rolling speed changes, the friction force on the strip changes, and the rolling force of the roll system is not in the vertical direction. In other words, during tension rolling, the impact load of the hot rolling mill is extremely large when it bites into the strip, and the bearing bracket will impact the mill housing, which will degrade the stability of the rolling mill system, and the rolling force of the rolling mill rolls does not act in the vertical direction. Therefore, to improve the accuracy of a vibration model of the hot rolling mill, the nonlinear vibration factors of the rolling mill rolls in the horizontal direction must be considered. Consequently, by considering the effect of the nonlinear force of the rolling mill in the vertical and horizontal directions and combining it with rolling mill vibration, we can better explore the chatter mechanism and vibration behavior of a hot rolling mill.

2.1. Nonlinear Spring Force of the Hydraulic Cylinder. A hydraulic cylinder has many advantages in practical application and is widely used in the hydraulic screwdown device of a rolling mill. In this study, we consider a double-acting single-piston servo hydraulic cylinder in a hot rolling mill as an example for the analysis; its structure diagram is presented in Figure 2.

As Figure 2 shows, $A_{1}$ and $A_{2}$ are the effective areas of piston rodless cavity and rod cavity of the hydraulic cylinder, respectively. $V_{L 1}$ and $V_{L 2}$ are the volumes of oil in the pipeline between the valve and the rodless cavity and between the valve and the rod cavity, respectively. $L$ is the total stroke of the hydraulic cylinder, $L_{0}$ is the initial position of the piston, $y$ is the piston displacement, which is also the vibration displacement in the vertical direction of the rolling mill rolls, and $k(y)$ is the total hydraulic spring stiffness of the hydraulic cylinder.

During the working of the hydraulic cylinder, the piston can be regarded as a rigid body. The change in the piston displacement changes the pressure and oil volume in the two oil cavities, changing the oil stiffness accordingly. Therefore, 


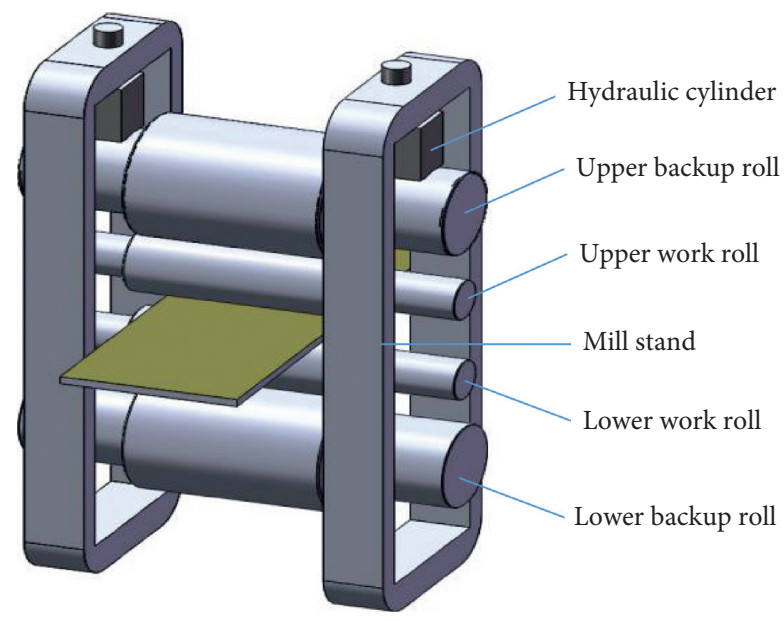

Figure 1: Structure of 1780 hot rolling mill.

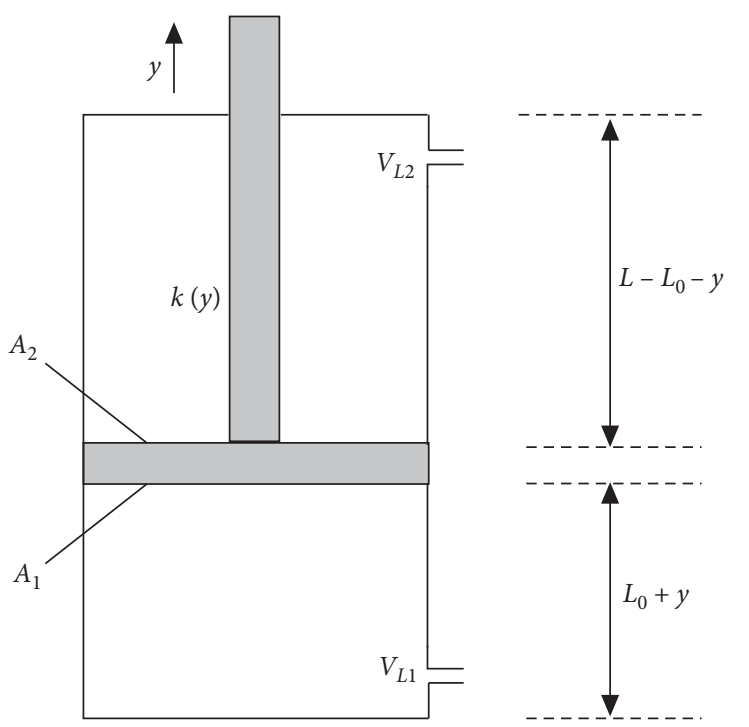

FIGURE 2: Structure diagram of a double-acting single-piston servo hydraulic cylinder.

$k(y)$ is equivalent to the parallel stiffness of the two chamber's hydraulic spring [19]:

$$
\begin{aligned}
k(y)= & \frac{\beta_{e} A_{1}^{2}}{V_{1}}+\frac{\beta_{e} A_{2}^{2}}{V_{2}}=\frac{\beta_{e} A_{1}^{2}}{A_{1}\left(L_{0}+y\right)+V_{L 1}} \\
& +\frac{\beta_{e} A_{2}^{2}}{A_{2}\left(L-L_{0}-y\right)+V_{L 2}},
\end{aligned}
$$

where $\beta_{e}$ is the elastic modulus of the oil volume and $V_{1}$ and $V_{2}$ are the volumes of the rodless cavity and rod cavity, respectively.

Because $V_{L 1}$ and $V_{L 2}$ are very small compared with the volumes of the two cavities and may be ignored, the spring stiffness of the hydraulic cylinder can be simplified as

$$
k(y)=\frac{\beta_{e} A_{1}}{L_{0}+y}+\frac{\beta_{e} A_{2}}{L-L_{0}-y} .
$$

Therefore, the spring stiffness of the hydraulic cylinder can be regarded as a function of vibration displacement, and the change law between them is shown in Figure 3.

By applying Taylor expansion to equation (2) at vibration displacement $y=0$, we obtain

$$
\begin{aligned}
k(y)= & \beta_{e} A_{1}\left(\frac{1}{L_{0}}-\frac{y}{L_{0}^{2}}+\frac{y^{2}}{L_{0}^{3}}\right) \\
& +\beta_{e} A_{2}\left(\frac{1}{L-L_{0}}-\frac{y}{\left(L-L_{0}\right)^{2}}+\frac{y^{2}}{\left(L-L_{0}\right)^{3}}\right)+O\left(y^{2}\right) .
\end{aligned}
$$

Due to the symmetry of spring potential energy $U(y)$ and by neglecting the odd power term, we obtain

$$
U(y)=\frac{1}{2} \alpha y^{2}+\frac{1}{4} \beta y^{4}
$$

where $\alpha=\left(\beta_{e} A_{1} / L_{0}\right)+\left(\beta_{e} A_{2} / L-L_{0}\right)$ and $\beta=\left(\beta_{e} A_{1} / L_{0}^{3}\right)+$ $\left(\beta_{e} A_{2} /\left(L-L_{0}\right)^{3}\right)$.

From the derivation of equation (4), the spring force of the hydraulic cylinder is

$$
F_{k}(y)=\alpha y+\beta y^{3}
$$

Equation (5) indicates that the spring force of the hydraulic cylinder is a nonlinear function of vibration displacement.

2.2. Nonlinear Friction and Dynamic Rolling Force. The calculation accuracy of rolling force greatly affects the distribution of friction force and strip quality in the deformation zone. Many expressions for rolling force under different working conditions have been proposed by analyzing, simplifying, and regressing the characteristics of nonlinear coupling vibration of the rolling mill and dynamic components of rolling force based on actual tests $[18,20]$. Of them, we adopt the Alexander-Ford formula for hot rolling [21]. The dynamic rolling process in the deformation zone is shown in Figure 4.

As Figure 4 shows, $\tau_{b}$ and $\tau_{f}$ are the tension at the entrance and exit of the rolling, respectively. $h_{0}$ and $h_{1}$ are the thickness at the entrance and exit of the workpiece in steady state, respectively. $h_{2}$ is the thickness at the exit of the workpiece in dynamic rolling, $h_{2}=h_{1}+y, v_{0}$ is the rotation speed of the roll, and $F_{\mu}$ is the friction force on the work rolls:

$$
P=\left(2 K-\frac{\tau_{b}+\tau_{f}}{2}\right) B Q_{p} l_{c}
$$

where $P$ is the rolling force, $K$ is the strip deformation resistance, $B$ is the average width of the workpiece, $Q_{p}$ is the influence coefficient of the stress state, and $l_{c}$ is the horizontal projection length of the roll contact arc in the deformation area: 


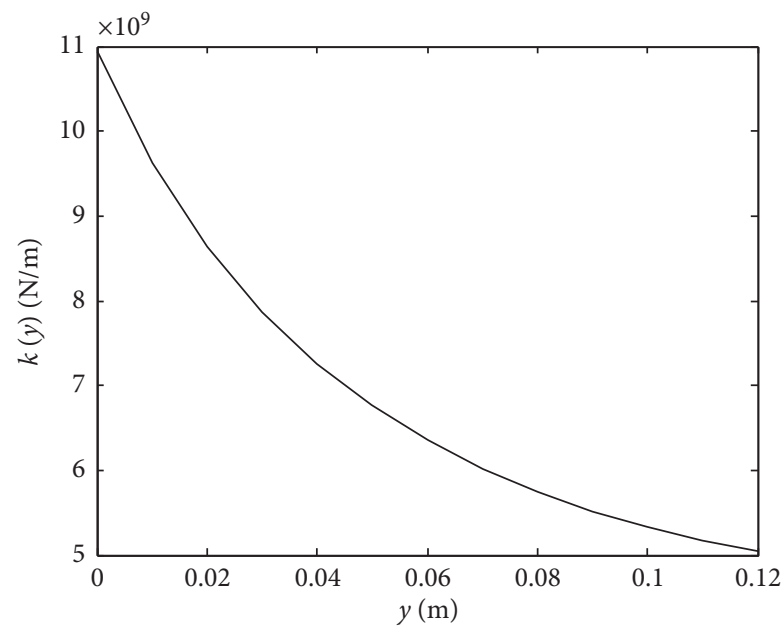

Figure 3: Curve of the spring stiffness with respect to the vibration displacement of the hydraulic cylinder.

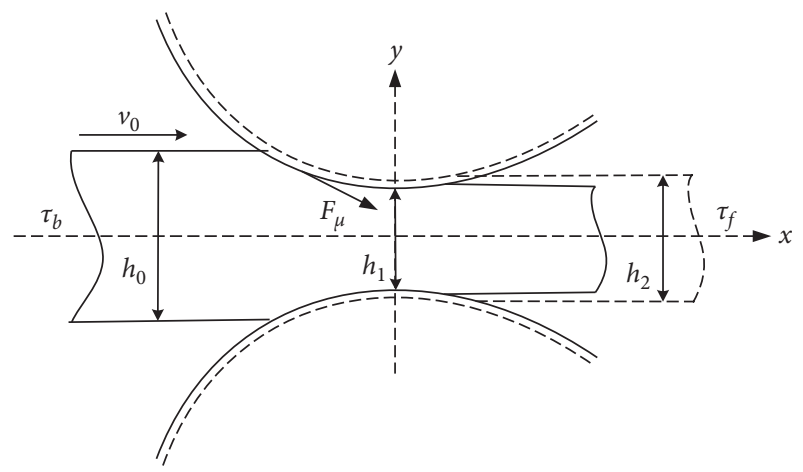

FIGURE 4: Dynamic rolling process in the deformation zone.

$$
\begin{aligned}
l_{c}= & \sqrt{R \Delta h}, \\
Q_{p}= & 1.08+1.79 \mu \delta \cdot \sqrt{1-\delta} \sqrt{\frac{R}{h_{2}}-1.02 \delta} \\
K= & 1.15 \sigma_{0} \exp \left(a_{1} T+a_{2}\right)\left(\frac{v_{0}}{10}\right)^{\left(a_{3} T+a_{4}\right)} a_{6}\left(\frac{e}{0.4}\right)^{a_{5}} \\
& -\left(a_{6}-1\right)\left(\frac{e}{0.4}\right),
\end{aligned}
$$

where $\Delta \mathrm{h}$ is the reduction, $\Delta h=h_{0}-h_{1}-y, R$ is the roll radius, and $\mu$ is the friction coefficient between rolls. $\delta$ is the reduction rate, $\delta=\Delta h / h 0, T$ is the deformation temperature, $T=(t 0+273) / 1000$, and $e$ is the deformation degree, $e=\ln [1 /$ $(1-\delta)]$. Regression coefficients $\sigma 0$ and a1-a 6 have a set of coefficients for different steel grades. In this study, the regression coefficient of the deformation resistance of ordinary carbon steel is taken [22] as follows:

$$
\begin{aligned}
& a_{1}=-2.878, a_{2}=3.665, a_{3}=0.1861, a_{4}=-0.1216, \\
& a_{5}=0.3795, a_{6}=1.402, \sigma_{0}=150.6 .
\end{aligned}
$$

Considering that the friction coefficient between roll gaps varies with the fluctuation of rolling speed during rolling, Robert's formula for friction coefficient is adopted [23]:

$$
\mu=\sqrt{\frac{\Delta h}{2 R}}\left(0.5+\left(G_{1}-0.5\right) e^{G_{2} v_{0}} e^{-G_{2} \dot{x}}\right)
$$

where $G_{1}$ and $G_{2}$ are the friction characteristic coefficients, whose values are determined by specific friction model parameters; generally, $G_{1}=0.51$ and $G_{2}=0.001 . \dot{x}$ is the vibration speed in the horizontal direction. Because $G_{2} \dot{x} \ll 1$, equation (9) can be changed to $\mu=\sqrt{(\Delta h / 2 R)}\left[0.5+\left(G_{1}-\right.\right.$ $\left.0.5) e^{G_{2} v_{0}}\left(1-G_{2} \dot{x}+G_{2} \dot{x}^{2} / 2\right)\right]$ and $y \leq h_{0}-h_{1}$; hence, equation (9) can be further expressed as

$$
\mu=\mu_{0}+\Delta \mu(\dot{x}, y)
$$

$$
\begin{aligned}
\Delta \mu(\dot{x}, y) & =-b_{1} \dot{x}+b_{2} \dot{x}^{2}-\left(b_{3}-b_{4} \dot{x}+b_{5} \dot{x}^{2}\right) y, \\
\mu_{0} & =g_{2}\left(0.5+g_{1}\right), \\
b_{1} & =g_{1} g_{2} G_{2}, \\
b_{2} & =\frac{g_{1} g_{2} G_{2}^{2}}{2}, \\
b_{3} & =\frac{0.5+g_{1}}{g_{3}}, \\
b_{4} & =g_{1} \frac{G_{2}}{g_{3}}, \\
b_{5} & =g_{1} \frac{G_{2}^{2}}{2 g_{3}}, \\
g_{1} & =\left(G_{1}-0.5\right) e^{G_{2} v_{0}}, \\
g_{2} & =\sqrt{\frac{\left(h_{0}-h_{1}\right)}{2 R}}, \\
g_{3} & =\sqrt{2 R\left(h_{0}-h_{1}\right)},
\end{aligned}
$$

where $\mu_{0}$ is the friction coefficient of the roll gap in the steady state and $\Delta \mu(\dot{x}, y)$ is the dynamic values of the friction coefficient. 
In steady-state rolling, the Taylor expansion of equation (6) at $\dot{x}=0$ and $y=0$ can be obtained as follows:

$$
\begin{aligned}
P & =P(0,0)+\Delta P(\dot{x}, y), \\
P(0,0) & =d_{0}=\left[2 K-\frac{\tau_{b+} \tau_{f}}{2}\right] B \sqrt{R\left(h_{0}-h_{1}\right)} Q_{p}^{\prime} \\
\Delta P(\dot{x}, y) & =d_{1} \dot{x}+d_{2} y+d_{3} \dot{x}^{2}+d_{4} \dot{x} y+d_{5} y^{2}, \\
Q_{p}^{\prime} & =1.08+\left(1.79 \mu_{0} \sqrt{\frac{R}{h_{0}}}-1.02\right) \frac{h_{0}-h_{1}}{h_{0}}, \\
d_{1} & =\frac{\partial}{\partial \dot{x}} P(0,0), \\
d_{2} & =\frac{\partial}{\partial y} P(0,0), \\
d_{3} & =\frac{1}{2 !} \frac{\partial^{2}}{\partial \dot{x}^{2}} P(0,0), \\
d_{4} & =\frac{\partial^{2}}{\partial x \partial y} P(0,0), \\
d_{5} & =\frac{1}{2 !} \frac{\partial^{2}}{\partial^{2} y} P(0,0) .
\end{aligned}
$$

Here $P(0,0)$ is the rolling force in the steady state of the vibration system of the hot rolling mill; $\Delta P(x, y)$ is the dynamic value of the rolling force in the unsteady state. Therefore, equation (12) is the nonlinear rolling force, which is affected by the coupling of vertical vibration displacement and horizontal vibration speed, as shown in Figure 5.

\subsection{Nonlinear Coupled Vibration Model of Hot Rolling Mill} Rolls. According to the structure diagram of the four-high hot rolling mill shown in Figure 1, we consider the structural constraints on the roll and the effect of dynamic rolling force, the nonlinear spring force exerted by the hydraulic cylinder in the vertical direction, and the friction force change caused by the rolling speed fluctuation in the horizontal direction. Then, the mass concentration method is adopted, wherein the upper backup and work rolls are equivalent to a mass block, while the lower backup and work rolls are equivalent to a mass block. At the same time, in the experiment, the vibration displacement of the upper and lower rolls of the rolling mill is the same, but in the opposite directions. For the convenience of calculation and analysis, owing to the symmetry of rolling mill vibration, the rolling mill can be simplified as an effective and reliable 2-DOF vibration system [24]. The coupling vibration model of the upper rolls of the hot rolling mill under multiple nonlinear effects is established, as shown in Figure 6.

As Figure 6 shows, $m$ is the equivalent mass of the upper roll system of the rolling mill, $v_{0}$ is the rotation speed of the work roll, $F_{0} \cos \omega t$ is the external excitation of the roll system, $F_{0}$ is the external excitation amplitude, and $\omega$ is the external excitation frequency. $k_{1}$ and $c_{1}$ are the equivalent stiffness and damping between the upper roll system and the frame and the archway column, respectively, and $k_{2}$ and $c_{2}$ are the equivalent stiffness and damping between the upper roll system and the steel strip, respectively.

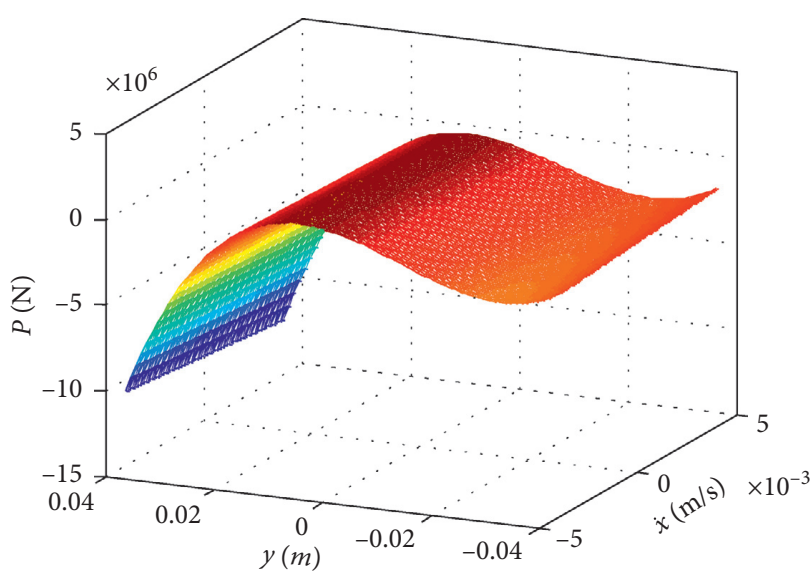

FIGURE 5: Curve of rolling force affected by the coupling of vertical vibration displacement and horizontal vibration velocity.

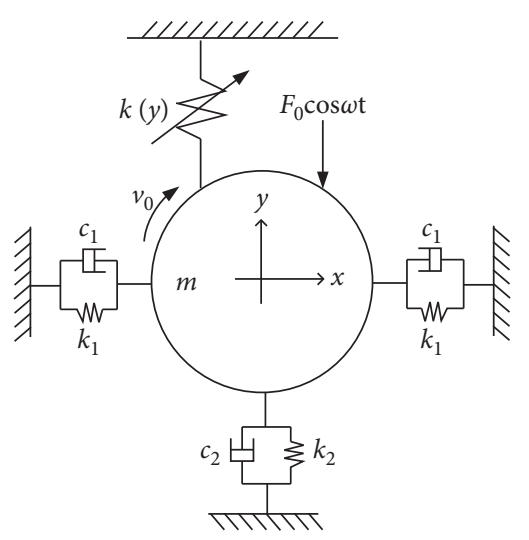

FIgURE 6: Nonlinear coupled vibration model of hot rolling mill rolls.

The friction on the roll is small in the vertical direction and can be neglected. Therefore, from equations (10) and (12), the nonlinear friction on the roll in the horizontal direction can be obtained as follows:

$$
F_{\mu}=\mu P=\mu_{0} P(0,0)+\Delta F_{\mu}(\dot{x}, y),
$$

where $\Delta F_{\mu}(\dot{x}, y)$ is the dynamic change of friction.

According to the Lagrange theory, the coupled vibration dynamic equation of the hot rolling mill rolls can be obtained as follows:

$$
\left\{\begin{array}{l}
m \ddot{x}+2 c_{1} \dot{x}+2 k_{1} x=\Delta F_{\mu}(\dot{x}, y), \\
m \ddot{y}+c_{2} \dot{y}+k_{2} y+\gamma F_{k}(y)=\Delta P(\dot{x}, y)+F_{0} \cos \omega t,
\end{array}\right.
$$

where $\ddot{x}$ and $\ddot{y}$ are the vibration accelerations in the horizontal and vertical directions, respectively. $\dot{x}$ and $\dot{y}$ are the vibration velocities in the horizontal and vertical directions, respectively. $x$ and $y$ are the vibration displacements in the horizontal and vertical directions, respectively, and $\gamma$ is the constraint coefficient of the nonlinear spring force. Therefore, equation (15) can be simplified as 


$$
\left\{\begin{array}{l}
\ddot{x}+\omega_{1}^{2} x=-c_{1}^{\prime} \dot{x}+\kappa_{1} y+\eta_{1} \dot{x}^{2}-\xi_{1} \dot{x} y-\varsigma_{1} y^{2}+\vartheta_{1} \dot{x}^{2} y \\
\quad+\rho_{1} \dot{x} y^{2}+\psi_{1} \dot{x}^{3}, \\
\ddot{y}+\omega_{2}^{2} y=-c_{2}^{\prime} \dot{y}+\kappa_{2} \dot{x}+\eta_{2} \dot{x}^{2}+\xi_{2} \dot{x} y+\varsigma_{2} y^{2} \\
\quad-\gamma \beta^{\prime} y^{3}+F_{0}^{*} \cos \omega t,
\end{array}\right.
$$

$$
\begin{aligned}
\omega_{1}^{2} & =\frac{2 k_{1}}{m}, \\
c_{1}^{\prime} & =\frac{2 c_{1}-\mu_{0} d_{1}+b_{1} d_{1}}{m}, \\
\kappa_{1} & =\frac{\mu_{0} d_{2}-b_{1} d_{2}}{m}, \\
\eta_{1} & =\frac{\mu_{0} d_{3}-b_{1} d_{3}}{m}, \\
\xi_{1} & =\frac{b_{3} d_{1}}{m}, \\
\varsigma_{1} & =\frac{b_{3} d_{2}}{m}, \\
\vartheta_{1} & =\frac{b_{4} d_{1}-b_{3} d_{3}+b_{2} d_{2}}{m}, \\
\rho_{1} & =\frac{b_{4} d_{2}}{m}, \\
\psi_{1} & =\frac{b_{2} d_{1}}{m}, \\
\omega_{2}^{2} & =\frac{k_{2}+\gamma \alpha-d_{2}}{m}, \\
c_{2}^{\prime} & =\frac{c_{2}}{m}, \\
\kappa_{2} & =\frac{d_{1}}{m}, \\
\eta_{2} & =\frac{d_{3}}{m}, \\
\xi_{2} & =\frac{d_{4}}{m}, \\
\varsigma_{2} & =\frac{d_{5}}{m}, \\
\beta^{\prime} & =\frac{\gamma \beta}{m}, \\
F_{0}^{*} & =\frac{F_{0}}{m} .
\end{aligned}
$$

\section{Solution of the Coupling Internal Resonance Response of Hot Rolling Mill Rolls}

The multiscale method has strong problem-solving ability and good computing ability, and considering that it is widely used in solving coupled vibration system problems, we use the multiscale method to solve the dynamic response of the system [25]. The nonlinear term in equation (16) is assigned a small parameter $\varepsilon$, and the fast and slow time scales $T_{0}=t$ and $T_{1}=\varepsilon t$, respectively, are introduced to obtain

$$
\left\{\begin{array}{l}
\frac{d}{\mathrm{~d} t}=D_{0}+\varepsilon D_{1}+\cdots, \\
\frac{d^{2}}{\mathrm{~d} t^{2}}=D_{0}^{2}+2 \varepsilon D_{0} D_{1}+\cdots,
\end{array}\right.
$$

where $D_{n}(n=0,1)$ is the partial differential sign, and $D_{n}=\partial /$ $\partial T_{n}$. The solution for equation (16) is set as follows:

$$
\left\{\begin{array}{l}
x=x_{0}\left(T_{0}, T_{1}\right)+\varepsilon x_{1}\left(T_{0}, T_{1}\right), \\
y=y_{0}\left(T_{0}, T_{1}\right)+\varepsilon y_{1}\left(T_{0}, T_{1}\right) .
\end{array}\right.
$$

Substituting equations (18) and (19) into equation (16), and separating the terms by the order of $\varepsilon$, we obtain

$$
\begin{aligned}
& \left\{\begin{array}{l}
D_{0}^{2} x_{0}+\omega_{1}^{2} x_{0}=0, \\
D_{0}^{2} y_{0}+\omega_{1}^{2} y_{0}=0,
\end{array}\right. \\
& \left\{\begin{array}{l}
D_{0}^{2} x_{1}+\omega_{1}^{2} x_{1}=-2 D_{0} D_{1} x_{0}-c_{1}^{\prime} D_{0} x_{0}+\kappa_{1} y_{0} \\
\quad+\eta_{1}\left(D_{0} x_{0}\right)^{2}-\xi_{1} y_{0} D_{0} x_{0}-\varsigma_{1} y_{0}^{2}+\vartheta_{1} y_{0}\left(D_{0} x_{0}\right)^{2} \\
\quad+\rho_{1} y_{0}^{2} D_{0} x_{0}+\psi_{1}\left(D_{0} x_{0}\right)^{3} \\
D_{0}^{2} y_{1}+\omega_{2}^{2} y_{1}=-2 D_{0} D_{1} y_{0}-c_{2}^{\prime} D_{0} y_{0}+\kappa_{2} D_{0} x_{0} \\
\quad+\eta_{2}\left(D_{0} x_{0}\right)^{2}+\xi_{2} y_{0} D_{0} x_{0}+\varsigma_{2} y_{0}^{2} \\
\quad-\gamma \beta^{\prime} y_{0}^{3}+F_{0}^{*} \cos \omega T_{0} .
\end{array}\right.
\end{aligned}
$$

The solution of equation (20) is set as follows:

$$
\left\{\begin{array}{l}
x_{0}=A\left(T_{1}\right) e^{i \omega_{1} T_{0}}+c c \\
y_{0}=B\left(T_{1}\right) e^{i \omega_{2} T_{0}}+c c
\end{array}\right.
$$

where $A$ and $B$ are the undetermined complex functions and $c c$ is the complex conjugate of the left side items. By substituting equation (22) in equation (21), we obtain 


$$
\left\{\begin{array}{l}
D_{0}^{2} x_{1}+\omega_{1}^{2} x_{1}=\left(-2 i \omega_{1} D_{1} A-i \omega_{1} c_{1}^{\prime} A+2 i \rho_{1} \omega_{1} A B \bar{B}+3 i \psi_{1} \omega_{1}^{3} A^{2} \bar{A}\right) e^{i \omega_{1} T_{0}} \\
+\left(\kappa_{1} B+2 \vartheta_{1} A \bar{A} B\right) e^{i \omega_{2} T_{0}}-i \omega_{1} \xi_{1} A B e^{i\left(\omega_{1}+\omega_{2}\right) T_{0}}+i \omega_{1} \xi_{1} \bar{A} B e^{i\left(\omega_{1}-\omega_{2}\right) T_{0}} \\
-\omega_{1}^{2} \vartheta_{1} A^{2} B e^{i\left(\omega_{2}+2 \omega_{1}\right) T_{0}}-\omega_{1}^{2} \vartheta_{1} \bar{A}^{2} B e^{i\left(\omega_{2}-2 \omega_{1}\right) T_{0}}+i \omega_{1} \rho_{1} A B^{2} e^{i\left(2 \omega_{2}+\omega_{1}\right) T_{0}} \\
-i \omega_{1} \rho_{1} \bar{A} B^{2} e^{i\left(2 \omega_{2}-\omega_{1}\right) T_{0}}-i \omega_{1}^{3} \psi_{1} A^{3} e^{3 i \omega_{1} T_{0}}-\eta_{1} \omega_{1}^{2} A^{2} e^{2 i \omega_{1} T_{0}}-\varsigma_{1} B^{2} e^{2 i \omega_{2} T_{0}} \\
+2 \omega_{1}^{2} \eta_{1} A \bar{A}-2 \varsigma_{1} B \bar{B}+c c, \\
D_{0}^{2} y_{1}+\omega_{2}^{2} y_{1}=\left(-2 i \omega_{2} D_{1} B-i \omega_{2} c_{2}^{\prime} B-3 \gamma \beta_{2} B^{2} \bar{B}\right) e^{i \omega_{2} T_{0}}+i \omega_{1} \kappa_{2} A e^{i \omega_{1} T_{0}} \\
+i \omega_{1} \xi_{2} A B e^{i\left(\omega_{1}+\omega_{2}\right) T_{0}}-i \omega_{1} \xi_{2} \bar{A} B e^{i\left(\omega_{2}-\omega_{1}\right) T_{0}}-\eta_{2} \omega_{1}^{2} A^{2} e^{2 i \omega_{1} T_{0}}+\varsigma_{2} B^{2} e^{2 i \omega_{2} T_{0}} \\
-\gamma \beta^{\prime} B^{3} e^{3 i \omega_{2} T_{0}}+2 \omega_{1}^{2} \eta_{2} A \bar{A}+2 \varsigma_{2} B \bar{B}+\frac{F_{0}^{*} e^{i \omega T_{0}}}{2}+c c .
\end{array}\right.
$$

Considering the internal resonance of the system, $\omega=\omega_{2}+\varepsilon \delta$ and $\omega_{1}=\omega_{2}+\varepsilon \delta_{1}$ are set, where $\delta$ and $\delta_{1}$ are the tuning parameters; $\delta$ can better describe the change between $\omega$ and $\omega_{2}$ and represent the value range between them. To avoid the duration term, $A$ and $B$ must satisfy the following:

$$
\left\{\begin{array}{l}
-2 i \omega_{1} D_{1} A-i \omega_{1} c_{1}^{\prime} A+2 i \rho_{1} \omega_{1} A B \bar{B}+3 i \psi_{1} \omega_{1}^{3} A^{2} \bar{A} \\
+\left(\kappa_{1} B+2 \vartheta_{1} A \bar{A} B\right) e^{-i \delta_{1} T_{1}}=0, \\
-2 i \omega_{2} D_{1} B-i \omega_{2} c_{2}^{\prime} B-3 \gamma \beta^{\prime} B^{2} \bar{B}+i \omega_{1} \kappa_{2} A e^{i \delta_{1} T_{1}} \\
+\frac{F_{0}^{*} e^{i \delta T_{1}}}{2}=0 .
\end{array}\right.
$$

We set $A=(1 / 2) a\left(T_{1}\right)^{i \phi_{1} T_{1}}$ and $B=(1 / 2) b\left(T_{1}\right) e^{i \phi_{2} T_{1}}$, where $a$ and $b$ are the amplitudes of rolling mill rolls in the horizontal and vertical directions, respectively. Substituting $A$ and $B$ into equation (24) and separating the real and imaging parts, the average equation of the coupling system can be obtained as follows:

$$
\left\{\begin{array}{l}
\dot{a}=-\frac{1}{2} c_{1}^{\prime} a+\frac{1}{4} \rho_{1} a b^{2}+\frac{3}{8} \psi_{1} \omega_{1}^{2} a^{3}+\frac{1}{\omega_{1}}\left(\frac{1}{2} \kappa_{1}+\frac{1}{4} \vartheta_{1} a^{2}\right) b \sin \theta_{1}, \\
a\left(\dot{\theta}_{1}+\dot{\theta}_{2}\right)=\left(\delta-\delta_{1}\right) a-\frac{1}{\omega_{1}}\left(\frac{1}{2} \kappa_{1}+\frac{1}{4} \vartheta_{1} a^{2}\right) b \cos \theta_{1}, \\
\dot{b}=-\frac{1}{2} c_{2}^{\prime} b+\frac{\omega_{1}}{\omega_{2}} \kappa_{2} a \cos \theta_{1}+\frac{F_{0}^{*}}{2} \sin \theta_{2}, \\
\dot{\theta}_{2}=\delta b-\frac{3}{8 \omega_{2}} \gamma \beta^{\prime} b^{3}-\frac{\omega_{1}}{\omega_{2}} \kappa_{2} a \sin \theta_{1}-\frac{F_{0}^{*}}{2} \cos \theta_{2}
\end{array}\right.
$$

where $\theta_{1}=\varphi_{2}-\varphi_{1}-\delta_{1} T_{1}$ and $\theta_{2}=\delta T_{1}-\varphi_{2}$. Considering the occurrence of a periodic movement in the coupling system of the hot rolling mill rolls, $\dot{a}=\dot{b}=\dot{\theta}_{1}=\dot{\theta}_{2}=0$ holds. Then, substituting this value into equation (25) and eliminating $\varphi_{1}$ and $\varphi_{2}$, the amplitude-frequency response equation of the coupling vibration system can be written as

$$
\left\{\begin{array}{l}
\left(-\frac{1}{2} c_{1}^{\prime}+\frac{1}{4} \rho_{1} b^{2}+\frac{3}{8} \psi_{1} \omega_{1}^{2} a^{2}\right)^{2} a^{2}+\left(\delta-\delta_{1}\right)^{2} a^{2} \\
=\frac{1}{\omega_{1}^{2}}\left(\frac{1}{2} \kappa_{1}+\frac{1}{4} \vartheta_{1} a^{2}\right)^{2} b^{2} \\
\left(-\frac{1}{2} c_{2}^{\prime} b+M\left(\delta-\delta_{1}\right)\right)^{2}+\left[\delta b-\frac{3}{8 \omega_{2}} \gamma \beta^{\prime} b^{3}\right. \\
\left.-M\left(\frac{1}{2} c_{1}^{\prime}-\frac{1}{4} \rho_{1} b^{2}-\frac{3}{8} \psi_{1} \omega_{1}^{2} a^{2}\right)\right]^{2}=\left(\frac{F_{0}^{*}}{2}\right)^{2}
\end{array}\right.
$$

where $M=\omega_{1}^{2} \kappa_{2} a^{2} / \omega_{2}\left((1 / 2) \kappa_{1}+(1 / 4) \vartheta_{1} a^{2}\right) b$.

\section{Amplitude Frequency Characteristics of Coupled Vibration of Hot Rolling Mill Rolls}

Table 1 shows the relevant vibration parameters of the 1780 hot rolling mill to conduct simulation analysis.

Figure 7 shows the amplitude-frequency diagram of the coupling vibration rolls of the hot rolling mill as a function of tuning parameter $\delta$. Set initial value $\gamma \beta=1.05 e 12\left(\mathrm{~N} / \mathrm{m}^{-3}\right)$ and $\rho_{1}=-3.3$. An energy exchange process is observed between the vertical and the horizontal direction, which is a special phenomenon that occurs in response to internal resonance. When tuning parameter $\delta>-10 \mathrm{~Hz}$, amplitude $a$ in the horizontal direction basically remains constant, while 
TABLE 1: Structural and technological parameters of the 1780 hot rolling mill.

\begin{tabular}{lc}
\hline Parameters & Value \\
\hline$\beta_{e}(\mathrm{GPa})$ & 1.6 \\
$A_{1}\left(\mathrm{~m}^{2}\right)$ & 0.6361 \\
$A_{2}\left(\mathrm{~m}^{2}\right)$ & 0.3243 \\
$L(\mathrm{~m})$ & 0.110 \\
$L_{0}(\mathrm{~m})$ & 0.064 \\
$B(\mathrm{~m})$ & 1.5 \\
$R(\mathrm{~m})$ & 0.42 \\
$V_{0}\left(\mathrm{~m} \cdot \mathrm{s}^{-1}\right)$ & 2.5 \\
$\tau_{b}(\mathrm{MPa})$ & 5.5 \\
$\tau_{f}(\mathrm{MPa})$ & 3.8 \\
$H_{0}(\mathrm{~m})$ & 0.0141 \\
$H_{1}(\mathrm{~m})$ & 0.0082 \\
$t_{0}\left({ }^{\circ} \mathrm{C}\right)$ & 996 \\
$m(\mathrm{Kg})$ & $1.44 \times 10^{5}$ \\
$c_{1}\left(\mathrm{~N} \cdot \mathrm{s} \cdot \mathrm{m}^{-1}\right)$ & $5.20 \times 10^{3}$ \\
$k_{1}\left(\mathrm{~N} \cdot \mathrm{m}^{-1}\right)$ & $7.31 \times 10^{9}$ \\
$c_{2}\left(\mathrm{~N} \cdot \mathrm{s} \cdot \mathrm{m}^{-1}\right)$ & $8.85 \times 10^{5}$ \\
$k_{2}\left(\mathrm{~N} \cdot \mathrm{m}^{-1}\right)$ & $2.08 \times 10^{10}$ \\
$F_{0}(\mathrm{MN})$ & 0.55 \\
$\mathrm{E}$ & 0.01 \\
\hline
\end{tabular}

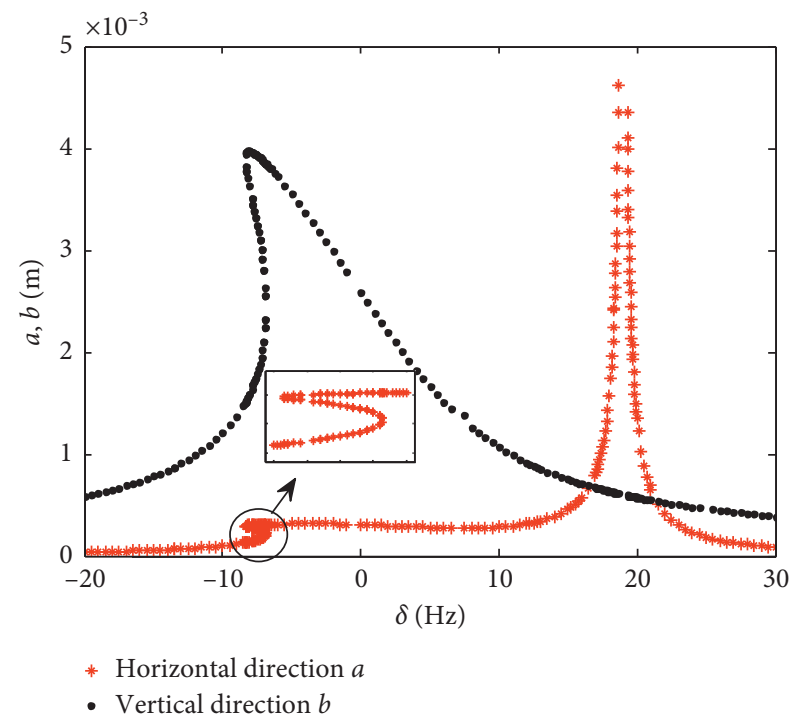

Figure 7: Amplitude-frequency curve of coupling vibration of the hot rolling mill roll system.

amplitude $b$ in the vertical direction increases rapidly and then decreases after reaching the maximum. When $16.5 \mathrm{~Hz}<\delta<21.5 \mathrm{~Hz}, a$ increases and $b$ decreases gradually. When $-8.40 \mathrm{~Hz}<\delta<-6.87 \mathrm{~Hz}$, there are multiple solutions in the two directions and a jump phenomenon exists, causing instability of the coupling vibration system of the rolling mill in this range. Due to external disturbance, $\omega_{1} \approx \omega_{2}$ and $\omega \approx \omega_{2}$, which imply that the external excitation frequency is close to the natural frequency in both directions and that resonance occurs. In addition, Figure 7 indicates a large linear frequency in the horizontal direction. This is because of the energy exchange to the horizontal direction when the vibration in the vertical direction is weakened.
Moreover, the external excitation frequency is similar to the natural frequency in the horizontal direction; therefore, the amplitude in the horizontal direction increases rapidly. The resonance can be avoided by changing the external excitation amplitude or the linear stiffness between the rolls to maintain each frequency separated from each other.

Figure 8 shows the amplitude-frequency curve of the coupling vibration of the hot rolling mill rolls under varying nonlinear spring force coefficient $\gamma \beta$ of the hydraulic cylinder for tuning parameter $\delta=14.5 \mathrm{~Hz}$. In the figure, stable branches are plotted with solid lines, while unstable branches are plotted with dotted lines. When $\gamma \beta=0$, that is, when the hydraulic cylinder piston is at the initial position, the vertical vibration of the rolling mill is only affected by the linear stiffness between the stands, and the amplitude of the vibration system is small. At this point, the rolling mill is in a steady state. With the increase in the piston movement displacement of the hydraulic cylinder, the corresponding nonlinear stiffness increases. For $\gamma \beta \geq 2.605 e 12\left(\mathrm{~N} / \mathrm{m}^{-3}\right)$, there are multiple solutions, the amplitude increases, and the resonance region expands. This indicates that the change in the piston position of the hydraulic cylinder greatly affects the vibration state of the rolling mill rolls. In actual rolling, hydraulic oil with good temperature characteristics and large bulk modulus of elasticity should be used as much as possible. Moreover, seals with good performance should be selected to prevent an increase in the level of impurities due to the long-term use of oil. However, the change in nonlinear stiffness is caused by the change in viscosity, leading to abnormal vibration.

Figure 9 shows the amplitude-frequency curve of the coupling vibration of the hot rolling mill rolls under varying coupling term parameter $\rho_{1}$, which is composed of horizontal vibration speed $\dot{x}$ and vertical vibration displacement $y$. In the plot, the stable branches are indicated with solid lines, and the unstable branches are indicated with dotted lines. For tuning parameter $\delta=14.5 \mathrm{~Hz}$, when $-12<\rho_{1}<-3$, there are multiple solutions and the vibration amplitude increases gradually, causing severe vibration of rolling mill rolls. The vibration form of the rolling mill in this range of coupling parameter is complex and variable. As $\rho_{1}$ increases, the vibration state of the rolling mill gradually stabilizes. This further indicates that the study of the coupling vibration of the hot rolling mill rolls is meaningful and would provide some guiding significance to explain the vibration phenomenon of rolling mills.

\section{Bifurcation Characteristics of Coupling Vibration of Hot Rolling Mill Rolls}

In this study, using the bifurcation and chaos theory, we determine the critical value and parameter range from the bifurcation solution of the coupling vibration system of the hot rolling mill rolls, so as to restrain and avoid rolling mill vibration.

5.1. Bifurcation Characteristics of Vibration in the Vertical Direction. Figure 10 shows the dynamic bifurcation diagram of the vertical coupling vibration of the hot rolling mill 


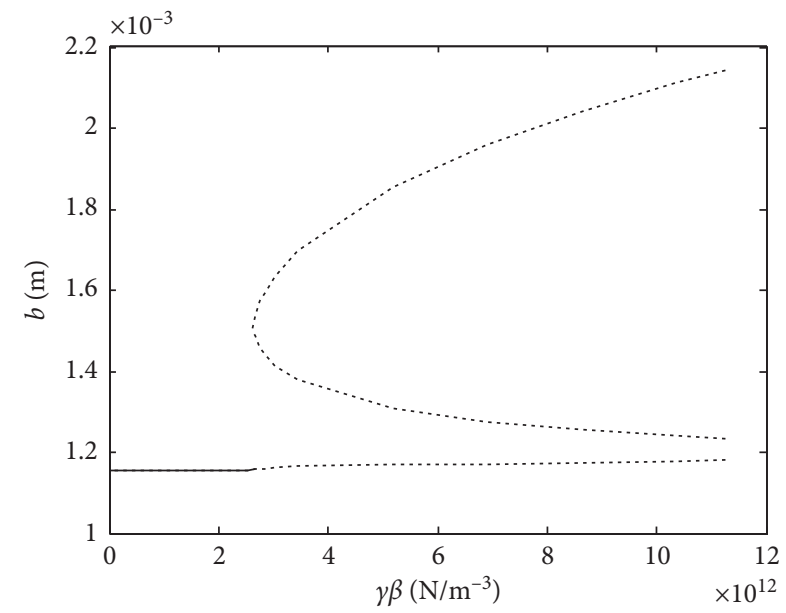

Figure 8: Amplitude-frequency curve of the rolling mill rolls as a function of parameter $\gamma \beta$.

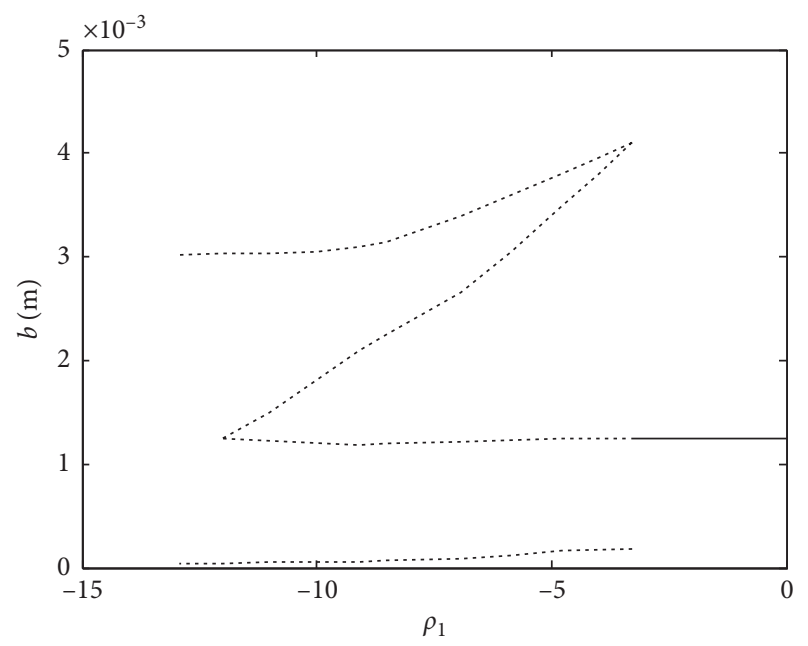

FIgURe 9: Amplitude-frequency curve of the rolling mill rolls as a function of coupling term parameter $\rho_{1}$.

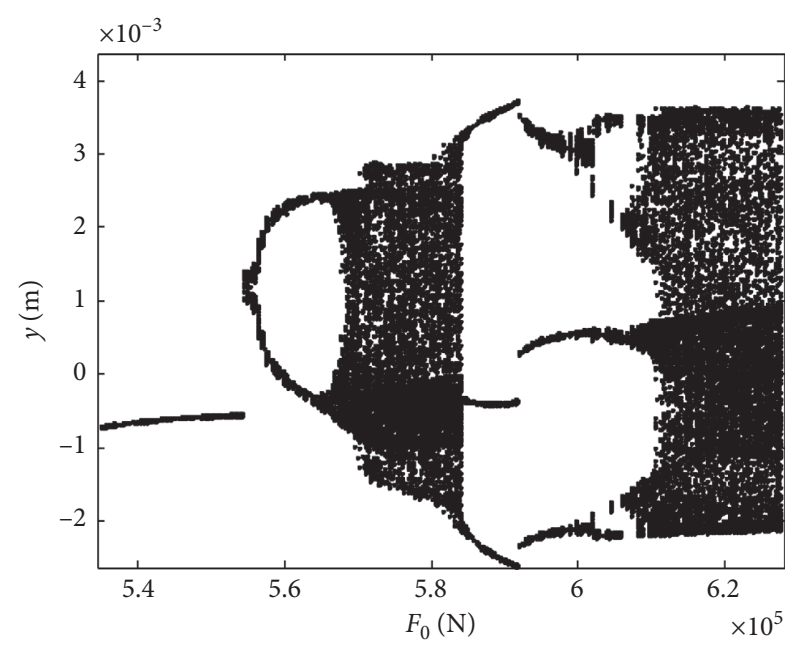

FIGURE 10: Bifurcation diagram of the vertical vibration under varying external excitation amplitude. rolls. Figures 11 and 12 show the phase path and the Poincare section under different external excitation amplitude $F_{0}$.

Figure 10 indicates that when the external excitation amplitude $F_{0}<5.54 e 5 \mathrm{~N}$, the vibration is period- 1 motion, the corresponding phase path is a closed curve (Figure 11(a)), and the corresponding Poincare section is a fixed point (Figure 12(a)). This implies that the vertical vibration of the rolling mill has a stable solution and the vibration displacement is small. With increasing $F_{0}$, the steady-state vibration becomes period-2 motion, the corresponding phase path is a closed curve formed after two circles (Figure 11(b)), and the Poincare section is two fixed points (Figure 12(b)). In this status, the vibration displacement of the rolling mill in the vertical direction increases gradually, resulting in an increase in the roll gap and the increase in the rolling workpiece reduction, causing uneven oscillation marks on the strip surface. With further increase in $F_{0}$, the vibration displacement will also increase. As shown in Figure 10, the system will enter into paroxysmal chaos, resulting in up and down vibration disorder of the rolling mill rolls, seriously affecting strip quality and aggravating oscillation marks. Therefore, the range $5.68 e 5 \mathrm{~N}<F_{0}<5.84 e 5 \mathrm{~N}$ should be avoided in an actual rolling process. Further, the vibration system degenerates into period-3 motion; the corresponding phase path is shown in Figure 11(c) and the Poincare section is shown in Figure 12(c). As $F_{0}$ continues to increase, there is a period-doubling bifurcation, that is, the vibration becomes period- 6 motion (Figures 11(d) and $12(\mathrm{~d})$ ), and when $F_{0}>6.12 e 5 \mathrm{~N}$, it will transform to chaos motion from period-doubling motion; the phase path is an open circular curve (Figure 11(e)), while the Poincare section is a set of many points (Figure 12(e)). This is because the vibration frequency of the external excitation gradually becomes close to or equal to the derived frequency of the rolling mill rolls, thus achieving resonance, which causes the amplitude of vertical vibration to attain the maximum value. Timely measures to restrain this resonance must be taken to prevent the occurrence of breakage of the steel strip.

\subsection{Bifurcation Characteristics of Vibration in the Horizontal} Direction. Figure 13 shows the dynamic bifurcation diagram of the horizontal vibration of the hot rolling mill rolls. Its specific vibration form is periodic- 1 motion $\longrightarrow$ periodic2 motion $\longrightarrow$ chaos motion $\longrightarrow$ degeneration to period-2 motion $\longrightarrow$ paroxysmal chaos $\longrightarrow$ chaos motion. The phase path and Poincare sections corresponding to different external excitation amplitudes $F_{0}$ are shown in Figures 14 and 15 .

When $F_{0}<5.31 e 5 \mathrm{~N}$, the horizontal vibration of the hot rolling mill is stable; the corresponding phase path is shown in Figure 14(a), and the Poincare section is shown in Figure $15(\mathrm{a})$. As $F_{0}$ gradually increases, the horizontal vibration system directly enters chaotic motion after period-2 motion, and when $F_{0}>5.95 e 5 \mathrm{~N}$, the system gradually degenerates into period-2 motion. The corresponding Poincare 


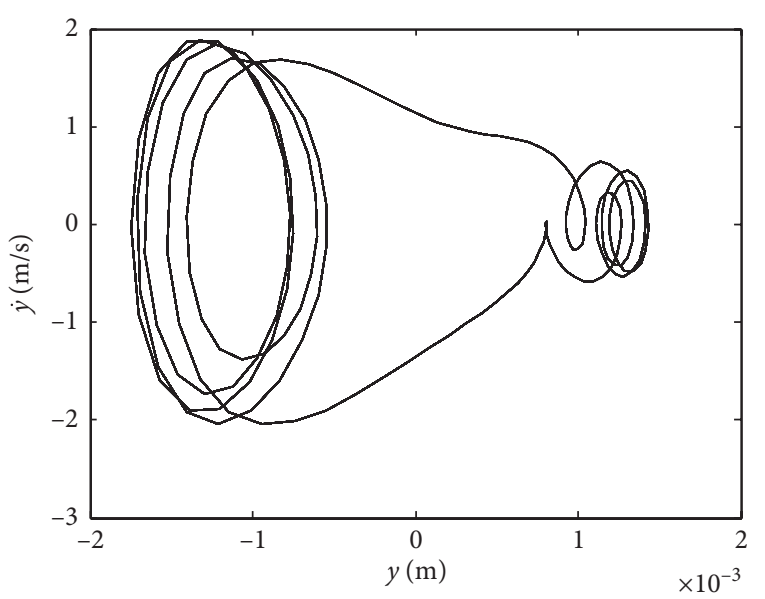

(a)

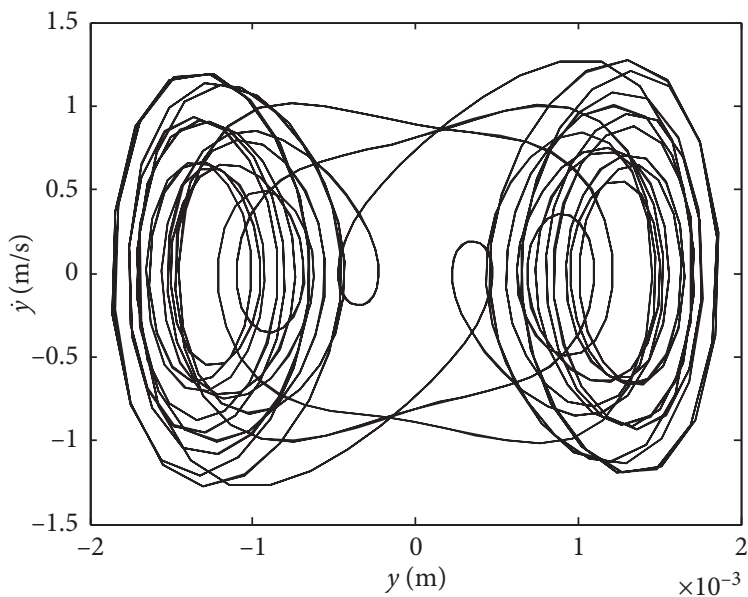

(c)

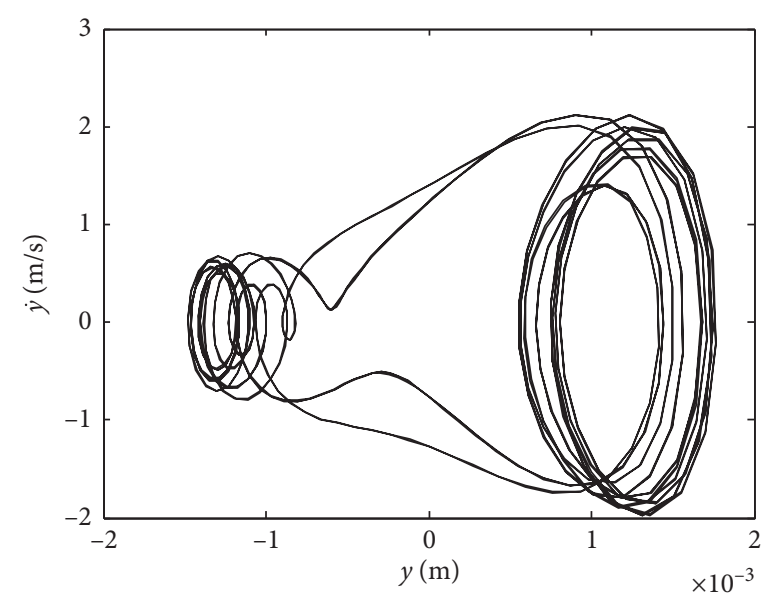

(b)

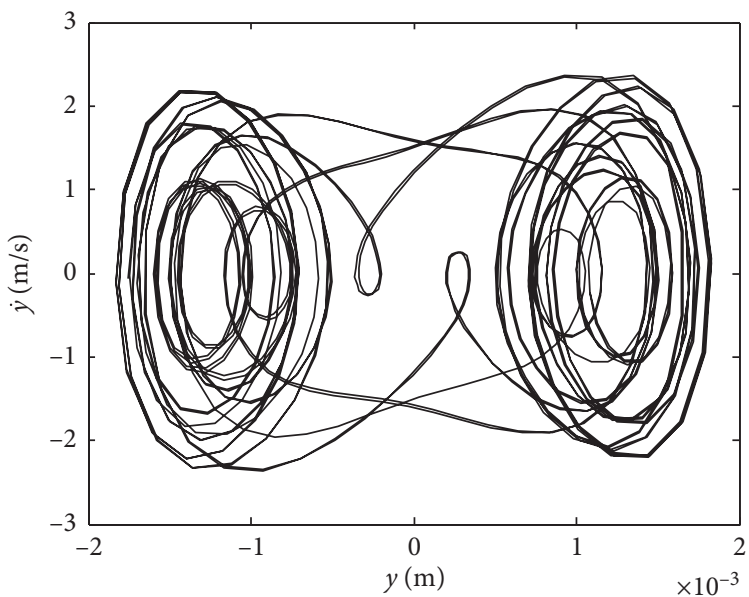

(d)

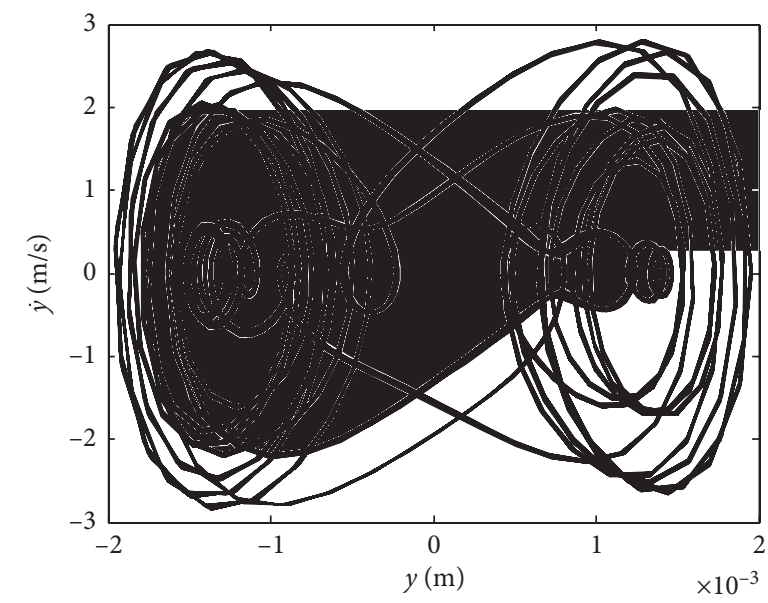

(e)

FiguRE 11: Phase path of the vertical vibration under varying external excitation amplitude: (a) $F_{0}=5.54 e 5 \mathrm{~N}$, (b) $F_{0}=5.60 e 5 \mathrm{~N}$, (c) $F_{0}=5.90 e 5$ $\mathrm{N},(\mathrm{d}) F_{0}=6.05 e 5 \mathrm{~N}$, and (e) $F_{0}=6.55 e 5 \mathrm{~N}$.

sections of the phase path are, respectively, shown in Figures 14(b) and 15(b). Then, the system passes through paroxysmal chaos when $F_{0}>6.20 e 5 \mathrm{~N}$, and it finally enters chaotic motion. The corresponding phase trajectory is shown in Figure 14(c). The trajectory is a set of unclosed curves, indicating that the system does not have periodicity at this time; the corresponding Poincare section is shown in Figure $15(\mathrm{c})$. Note that the system undergoes a periodic 


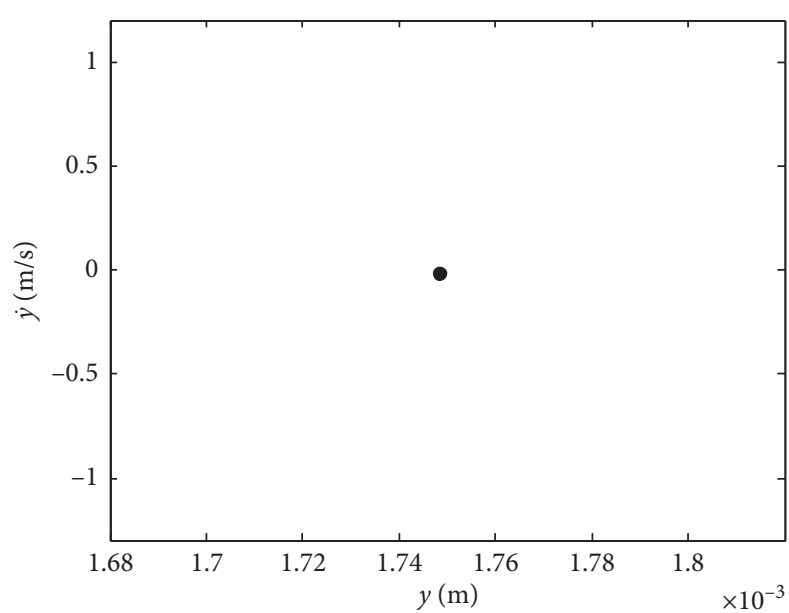

(a)

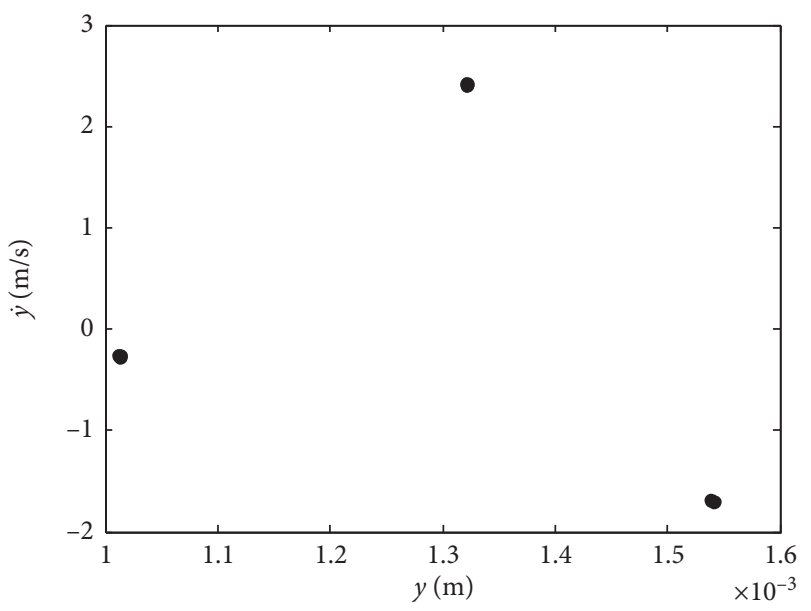

(c)

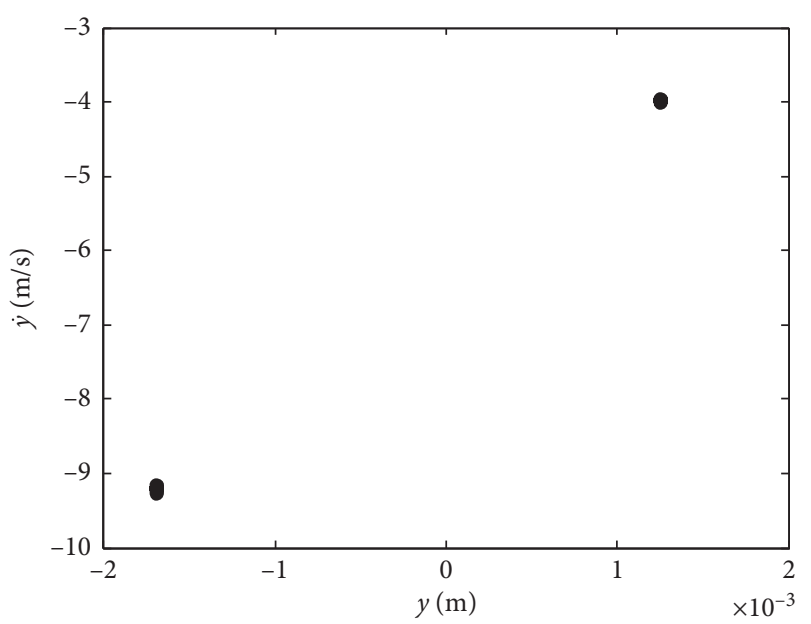

(b)

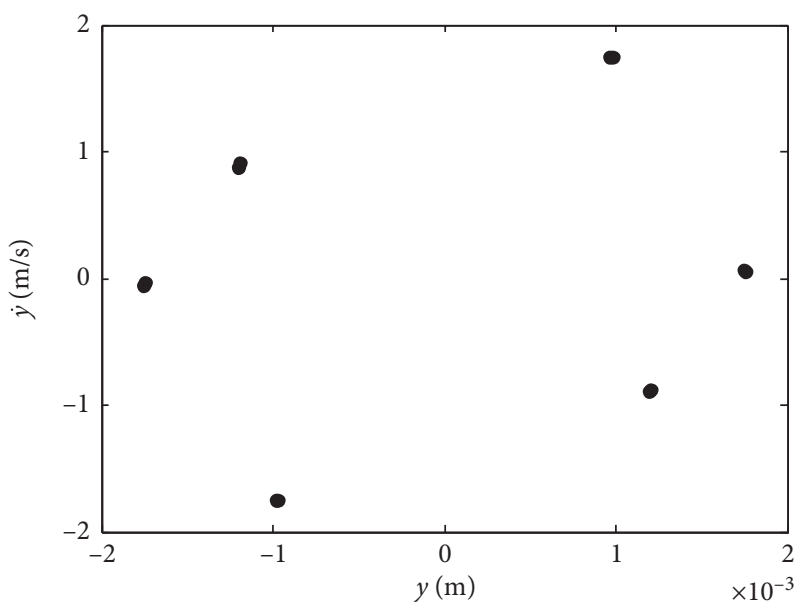

(d)

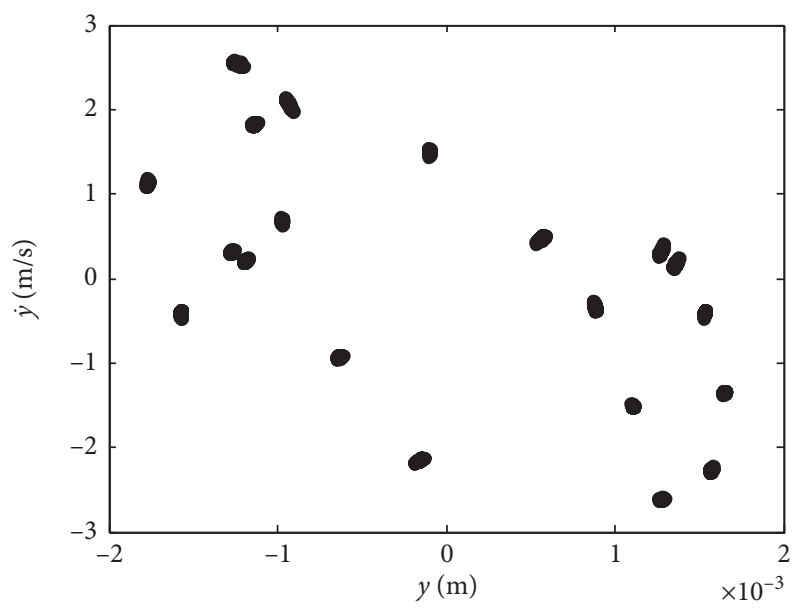

(e)

FIgURE 12: Poincare section of vertical vibration under varying external excitation amplitude: (a) $F_{0}=5.54 e 5 \mathrm{~N}$, (b) $F_{0}=5.60 e 5 \mathrm{~N}$, (c) $F_{0}=5.90 e \mathrm{~N},(\mathrm{~d}) F_{0}=6.05 e 5 \mathrm{~N}$, and (e) $F_{0}=6.55 e 5 \mathrm{~N}$.

motion, period-doubling motion, and chaotic motion in the horizontal direction, and the movement alternates among these forms. Thus, different forms of chatter marks are caused on the steel strip.
Figures 10 and 13 indicate that changes in the external excitation amplitude will cause changes in the vibration displacement in both vertical and horizontal directions. Therefore, fluctuation of the speed of the rolls is caused, which in turn 


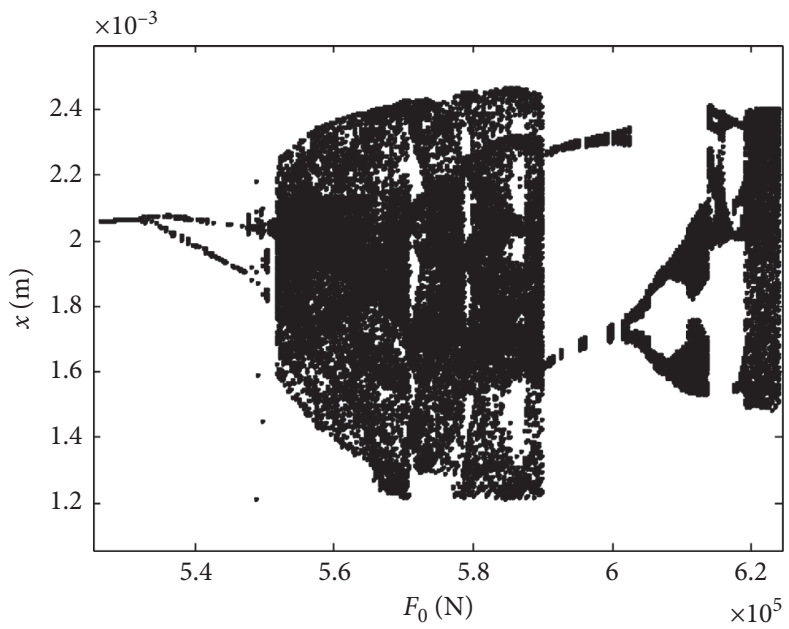

FIGURE 13: Bifurcation diagram of horizontal vibration of the hot rolling mill rolls under varying external excitation amplitude.

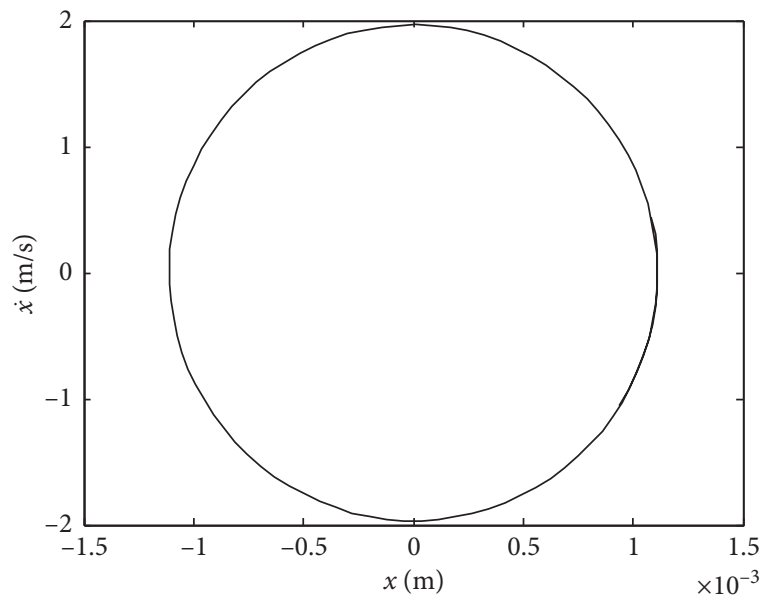

(a)

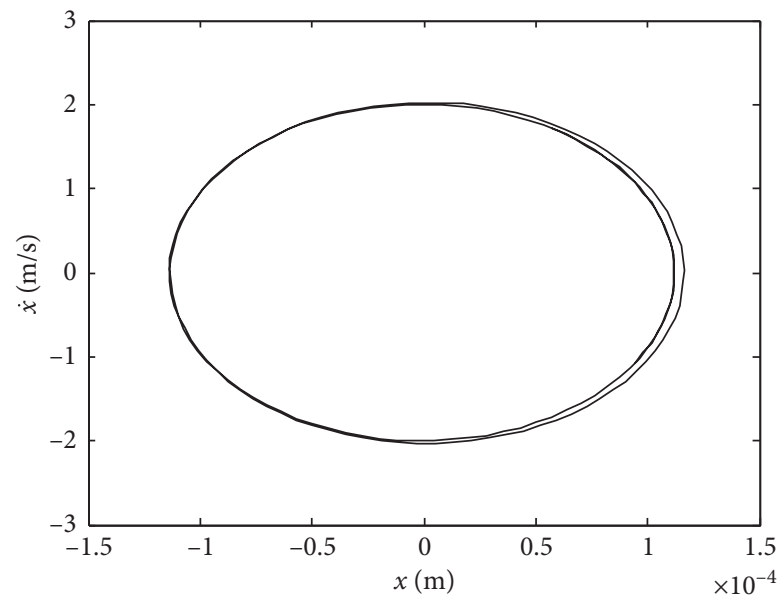

(b)

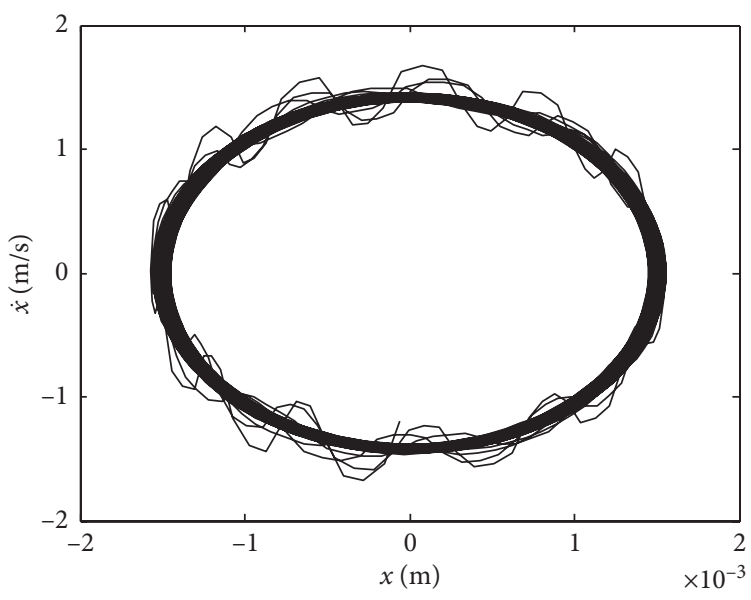

(c)

FIGURE 14: Phase paths of horizontal vibration of the rolling mill rolls under varying external excitation amplitude: (a) $F_{0}=5.31 e 5 \mathrm{~N},(\mathrm{~b})$ $F_{0}=5.95 e 5 \mathrm{~N}$, and (c) $F_{0}=6.20 e 5 \mathrm{~N}$.

leads to changes in nonlinear friction force and dynamic rolling force, resulting in abnormal vibration of the coupling system of the rolling mill rolls. Comparison of Figures 10 and 13 indicates that the two ranges of $F_{0}$, namely, $5.68 \mathrm{e} 5 \mathrm{~N}<F_{0}<5.84 e 5 \mathrm{~N}$ and $F_{0}>6.12 e 5 \mathrm{~N}$, can cause severe vibration of rolling mill rolls in the vertical and horizontal directions. 


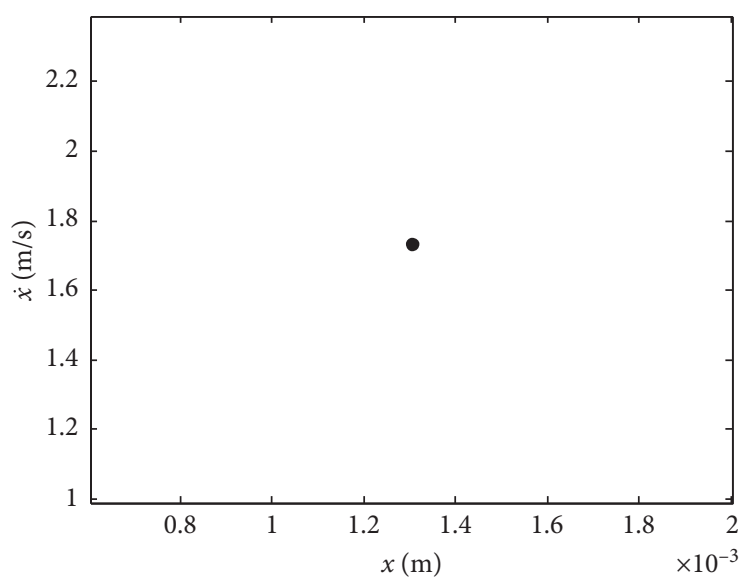

(a)

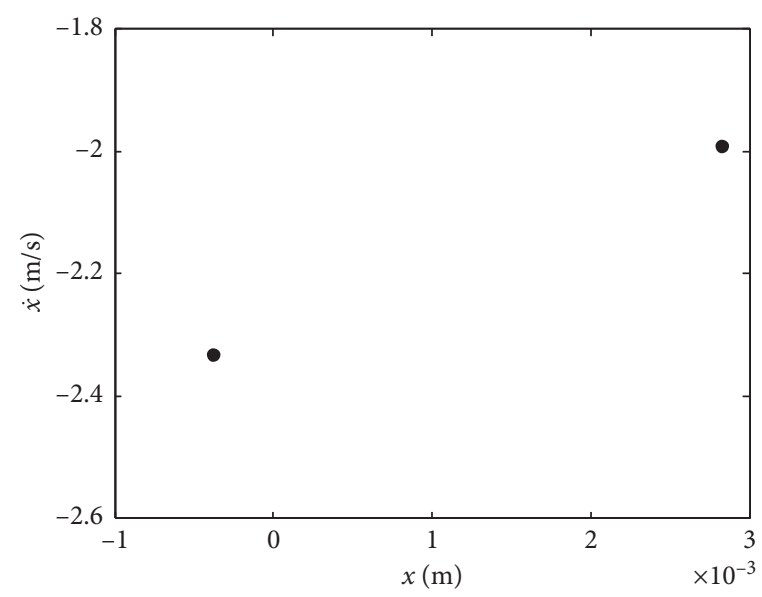

(b)

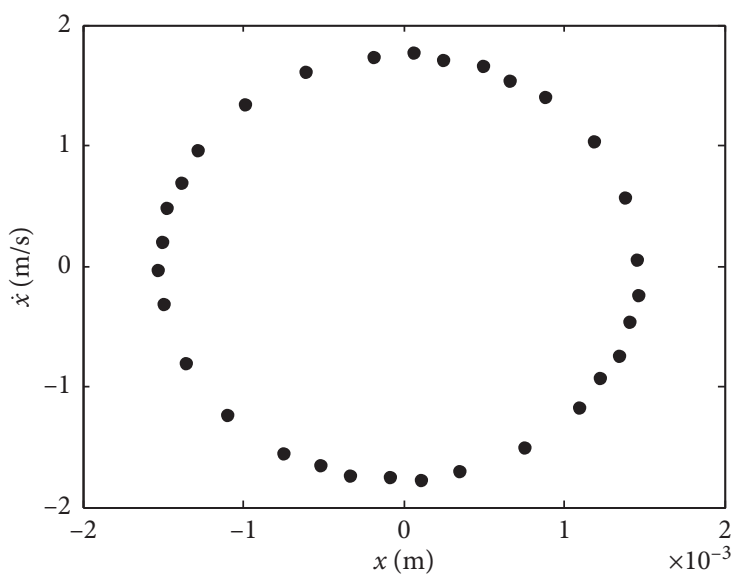

(c)

FIGURE 15: Poincare section of horizontal vibration of the rolling mill rolls under varying external excitation amplitude, (a) $F_{0}=5.31 e 5 \mathrm{~N}$, (b) $F_{0}=5.95 e 5 \mathrm{~N}$, and (c) $F_{0}=6.20 e 5 \mathrm{~N}$.

\section{Conclusions}

In this study, a coupled vibration model of hot rolling mill rolls under the effect of multiple nonlinear forces was established. Below is the summary of the analysis and steps involved in establishing the model.

(1) By analyzing the actual structure and working principle of a double-acting single-piston servo hydraulic cylinder, the nonlinear spring force produced by it was obtained. Considering the velocity fluctuation at the entry of the strip workpiece in the horizontal direction and the changes in the vibration displacement in the vertical direction, the nonlinear friction force between the rolls was obtained. Finally, by considering the dynamic variation of the rolling force, the coupling vibration model of a four-high hot rolling mill under the effect of multiple nonlinearity was established.

(2) Based on the amplitude-frequency response equation, and by using the actual rolling parameters of the 1780 four-high hot rolling mill, the main reason for the severe resonance of the rolling mill was found to be the occurrence of the internal resonance when the external excitation frequency is close to the derived frequency in the vertical and horizontal directions. This results in the instability of the system and occurrence of the jump phenomenon. Further, changes in the movement displacement of the hydraulic cylinder and the coupling term parameters considerably contribute to the changes in the amplitude and resonance range of the coupling vibration system of the hot rolling mill rolls.

(3) From the study of the bifurcation characteristics of the coupled vibration system of the hot rolling mill under varying external excitation amplitude, it was found that period and period-doubling motions exist in both vertical and horizontal directions, and the vibration alternates between different forms. Therefore, periodic light and dark stripes appear on the strip. The results indicate that the abnormal vibration of rolling mill rolls can be mitigated if the external excitation amplitude is maintained below the critical value. 


\section{Data Availability}

The structural and technological data of rolling mill used to support the findings of this study are included within the article.

\section{Conflicts of Interest}

The authors declare that there are no conflicts of interest regarding the publication of this paper.

\section{Acknowledgments}

This research was supported by National Natural Science Foundation of China (Grant no. 61973262) and Hebei Province Natural Science Funds for the Joint Research of Iron and Steel (Grant no. E2019203146).

\section{References}

[1] U. Efrain, "Identification and countermeasures to resolve hot mill chatter," AISE Steel Technology, vol. 78, no. 6, pp. 48-52, 2001.

[2] X. X. Wang and X. Q. Yan, "Dynamic model of the hot strip rolling mill vibration resulting from entry thickness deviation and its dynamic characteristics," Mathematical Problems in Engineering, vol. 2019, Article ID 5868740, 11 pages, 2019.

[3] X. B. Fan, Y. Zang, and K. Jin, "Rolling process and its influence analysis on hot continuous rolling mill vibration," Applied Physics-Materials Science \& Processing, vol. 122, no. 12, Article ID 1008, 2016.

[4] J. Sun, Y. Hu, F. Yin, Y. Hu, W. Peng, and D. Zhang, "Loopergauge integrated control in hot strip finishing mill using inverse linear quadratic theory," ISIJ International, vol. 59, no. 9, pp. 1562-1572, 2019.

[5] X. B. Fan, Y. Zang, Y. K. Sun, and P. A. Wang, "Impact analysis of roller system stability for four-high mill horizontal vibration," Shock and Vibration, vol. 2016, Article ID 5693584, 10 pages, 2016.

[6] P.-M. Shi, J.-Z. Li, J.-S. Jiang, B. Liu, and D.-Y. Han, "Nonlinear dynamics of torsional vibration for rolling mill's main drive system under parametric excitation," Journal of Iron and Steel Research International, vol. 20, no. 1, pp. 7-12, 2013.

[7] D. Y. Han, P. M. Shi, and K. W. Xia, "Nonlinear torsional vibration dynamics behaviors of rolling mill's multi-DOF main drive system under parametric excitation," Journal of Applied Mathematics, vol. 2014, Article ID 202686, 7 pages, 2014.

[8] D. X. Hou, R. R. Peng, and H. R. Liu, "Analysis of verticalhorizontal coupling vibration characteristics of rolling mill rolls based on strip dynamic deformation process," Shock and Vibration, vol. 2014, Article ID 543793, 11 pages, 2014.

[9] S. Liu, Z. L. Wang, J. J. Wang, and H. B. Li, "Sliding bifurcation research of a horizontal-torsional coupled main drive system of rolling mill," Nonlinear Dynamics, vol. 83, no. 1-2, pp. 441-455, 2016.

[10] L. Q. Zeng, Y. Zang, and Z. Y. Gao, "Hopf bifurcation control for rolling mill multiple-mode-coupling vibration under nonlinear friction," Journal of Vibration and AcousticsTransactions of the ASME, vol. 139, no. 6, Article ID 061015, 2017.
[11] Y. Peng, M. Zhang, J.-L. Sun, and Y. Zhang, "Experimental and numerical investigation on the roll system swing vibration characteristics of a hot rolling mill," ISIJ International, vol. 57, no. 9, pp. 1567-1576, 2017.

[12] J. L. Sun, Y. Peng, and H. M. Liu, "Coupled dynamic modeling of rolls model and metal for four high mill based on strip crown control," Chinese Journal of Mechanical Engineering, vol. 26, no. 1, pp. 144-150, 2012.

[13] I.-S. Yun, W. R. D. Wilson, and K. F. Ehmann, "Chatter in the strip rolling process, Part 1: dynamic model of rolling," Journal of Manufacturing Science and Engineering, vol. 120, no. 2, pp. 330-336, 1998.

[14] I.-S. Yun, K. F. Ehmann, and W. R. D. Wilson, "Chatter in the strip rolling process, part 2: dynamic rolling experiments," Journal of Manufacturing Science and Engineering, vol. 120, no. 2, pp. 337-342, 1998.

[15] X. Yang, C. N. Tong, G. F. Yue, and J. J. Meng, "Coupling dynamic model of chatter for cold rolling," Journal of Iron and Steel Research, vol. 17, no. 12, pp. 11-17, 2010.

[16] Z. Liu, J. Jiang, P. Li, G. Pan, and B. Liu, "Dynamic analysis and control of strip mill vibration under the coupling effect of roll and rolled piece," Journal of Vibroengineering, vol. 19, no. 8, pp. 6079-6093, 2017.

[17] Q. Wang, Z. Jiang, J. Zhao, and M. Fang, "Multi-factor coupling system characteristic of the dynamic roll gap in the high-speed rolling mill during the unsteady lubrication process," Tribology International, vol. 67, pp. 174-181, 2013.

[18] X. Lu, G. T. Li, Z. H. Wang, and D. H. Zhang, "Stability analysis of a nonlinear coupled vibration model in a tandem cold rolling mill," Shock and Vibration, vol. 2019, Article ID 4358631, 14 pages, 2019.

[19] Y. Zhu, P. F. Qian, S. N. Tang, W. L. Jiang, W. Li, and J. H. Zhao, "Amplitude-frequency characteristics analysis for vertical vibration of hydraulic AGC system under nonlinear action," AIP Advances, vol. 9, no. 3, Article ID 035019, 2019.

[20] J. Ji, "Stability of the coupled vibrations of work roll and strip in cold rolling process," Proceedings of the Institution of Mechanical Engineers, Part B: Journal of Engineering Manufacture, vol. 231, no. 7, pp. 1169-1181, 2015.

[21] Y. Peng, J. L. Sun, Y. Zhang, and M. Zhang, Dynamic Model System of Strip Mill Stable Operation and its Industrial Application, Mechanical Industry Press, Beijing, China, 2018.

[22] Y. K. Sun, Model and Control of Cold and Hot Rolling Strip Mill, Metallurgical Industry Press, Beijing, China, 2010.

[23] W. L. Roberts, "Third-octave-mode chatter in the cold rolling of light-gages strip," Proceedings International Conference on Steel Rolling, vol. 2, pp. 89-95, 1980.

[24] P.-H. Hu, H. Zhao, and K. F. Ehmann, "Third-octave-mode chatter in rolling. part 1: chatter model," Proceedings of the Institution of Mechanical Engineers, Part B: Journal of Engineering Manufacture, vol. 220, no. 8, pp. 1267-1277, 2006.

[25] A. H. Nayfeh, Perturbation Methods, Wiley-Interscience, New York, NY, USA, 1973. 